\title{
Bladder Cancer pNO TNM Finding v8
}

National Cancer Institute

\section{Source}

National Cancer Institute. Bladder Cancer pNO TNM Finding v8. NCI Thesaurus. Code C140409.

Bladder cancer with no lymph node metastasis. (from AJCC 8th Ed.) 